\begin{tabular}{|c|l|}
\hline Title & $\begin{array}{l}\text { Purvalanol A enhances cell killing by inhibiting up-regulation of CDC2 kinase activity in tumor cells irradiated with } \\
\text { high doses of X rays. }\end{array}$ \\
\hline Author(s) & I izuka, Daisuke; Inanami, O samu; Kashiwakura, Ikuo; Kuwabara, Mikinori \\
\hline Citation & $\begin{array}{l}\text { Radiation Research, 167(5), 563-571 } \\
\text { https://doi.org/10.1667/RR0622.1 }\end{array}$ \\
\hline Issue Date & 2007-05 \\
\hline Doc URL & http:/hdl.handle.net/2115/27975 \\
\hline Type & article \\
\hline File Information & RR167-5.pdf \\
\hline
\end{tabular}

Instructions for use 


\title{
Purvalanol A Enhances Cell Killing by Inhibiting Up-Regulation of CDC2 Kinase Activity in Tumor Cells Irradiated with High Doses of $\mathrm{X}$ Rays
}

\author{
Daisuke Iizuka, ${ }^{a}$ Osamu Inanami, ${ }^{a}$ Ikuo Kashiwakura ${ }^{b}$ and Mikinori Kuwabara ${ }^{a, 1}$ \\ ${ }^{a}$ Laboratory of Radiation Biology, Graduate School of Veterinary Medicine, Hokkaido University, Sapporo, 060-0818, Japan; and \\ ${ }^{b}$ Department of Radiological Technology, Hirosaki University School of Health Sciences, Hirosaki 036-8564, Japan
}

Iizuka, D., Inanami, O., Kashiwakura, I. and Kuwabara, M. Purvalanol A Enhances Cell Killing by Inhibiting Up-Regulation of CDC2 Kinase Activity in Tumor Cells Irradiated with High Doses of X Rays. Radiat. Res. 167, 563-571 (2007).

To clarify the relationship between CDC2 kinase activity and radiation-induced apoptosis, we examined whether the cyclin-dependent kinase (CDK) inhibitor purvalanol A enhanced radiation-induced apoptosis in gastric tumor cells. MKN45 cells exposed to $20 \mathrm{~Gy}$ of $\mathrm{X}$ rays increased the CDC2 kinase activity and the expression of regulatory proteins (phospho-CDC2 and cyclin B1) of the $G_{2} / M$ phase, followed by activation of the $G_{2} / M$ checkpoint, whereas the treatment of X-irradiated MKN45 cells with $20 \mu M$ purvalanol A suppressed the increase in the CDC2 kinase activity and expression of the $G_{2} / M$-phase regulatory proteins and reduced the fraction of the cells in the $G_{2} / M$ phase in the cell cycle. Furthermore, this treatment resulted in not only a significant increase in radiation-induced apoptosis but also the loss of clonogenicity in both MKN45 (p53-wild) and MKN28 (p53-mutated) cells. The expression of anti-apoptosis proteins, inhibitor of apoptosis protein (IAP) family members (survivin and XIAP) and BCL2 family members (Bcl- $\mathrm{X}_{\mathrm{L}}$ and $\left.\mathrm{Bcl}-2\right)$, in purvalanol $A$-treated cells with and without $X$ rays was significantly lower than for cells exposed to $X$ rays alone. These results suggest that the inhibition of radiation-induced CDC2 kinase activity by purvalanol $\mathrm{A}$ induces apoptosis through the enhancement of active fragments of caspase 3. @ 2007 by Radiation Research Society

\section{INTRODUCTION}

A number of advances in curing cancer in the last decade have come from successful combinations of conventional chemotherapeutic agents with radiation therapy (1). 1-(3C-Ethynyl- $\beta$-D-ribo-pentofuranosyl) cytosine (ECyd, TAS106) is a newly developed antitumor agent that targets RNA synthesis (2). We have reported that doses of ECyd of less than $5 \mu M$ radiosensitize both caspase-dependent apoptosis and reproductive death in cells of the gastric tu-

\footnotetext{
${ }^{1}$ Address for correspondence: Laboratory of Radiation Biology, Graduate School of Veterinary Medicine, Hokkaido University, Sapporo, 0600818, Japan; e-mail: kuwabara@vetmed.hokudai.ac.jp.
}

mor cell lines MKN45 and MKN28, murine rectum adenocarcinoma cell line Colon26, and Chinese hamster lung fibroblast cell line V79 $(3,4)$. Treatment of cells with ECyd at these concentrations, which are one order of magnitude lower than that used in single-agent therapy, showed little cytotoxicity. In ECyd-enhanced radiation-induced apoptosis, down-regulation of the $\mathrm{G}_{2} / \mathrm{M}$ checkpoint-related proteins and anti-apoptosis proteins, i.e., phosphorylated CDC2, WEE1, cyclin B1, survivin, Bcl- $\mathrm{X}_{\mathrm{L}}$ and $\mathrm{BCL} 2$, was found to be important in various cell lines. However, it is still unclear which molecule among these proteins plays a crucial role in sensitization to radiation-induced apoptosis by ECyd because of its nonspecific inhibitory effect on RNA synthesis in tumor cells.

Recently, it was reported that a $\mathrm{G}_{2} / \mathrm{M}$ checkpoint regulator, $\mathrm{CDC} 2$, controlled the activity of the anti-apoptosis protein survivin (5). Survivin is strongly expressed in the $\mathrm{G}_{2} / \mathrm{M}$ phase and undergoes cell cycle-dependent phosphorylation on Thr34 by a CDC2-cyclin B1 complex to make a complex with caspase 3 on the mitotic apparatus. The loss of this phosphorylation results in dissociation of the survivin/caspase 3 complex, followed by the induction of caspase 3-dependent apoptosis in cells traversing mitosis (5). The apoptosis induced by the anti-tumor drugs Taxol (6) and flavopilidol (7) was reported to be enhanced by the overexpression of dominant negative T34A survivin (threonine to alanine at codon 34) in tumor cells, suggesting that the activity of $\mathrm{CDC} 2$ prevented apoptosis through phosphorylation of survivin.

In the present study, to obtain direct evidence that the activity of CDC2 kinase was associated with the maintenance of an anti-apoptosis system in X-irradiated tumor cells, the purine analog derivative purvalanol $\mathrm{A}$, which is a CDK inhibitor, was used. Purvalanol A was recently developed as a protein kinase inhibitor with high selectivity for CDC2 (CDK1) through competitive inhibition of ATP binding $(8,9)$. A previous report showed that cotreatment with purvalanol A and Taxol, a microtubule stabilizing agent, enhanced apoptosis through the inhibition of CDC2 kinase activity (10). There has been no report on the enhancement of radiation-induced apoptosis and loss of clonogenic ability caused by the inhibition of CDC2 kinase ac- 
tivity. We report here that purvalanol A enhances radiationinduced apoptosis and reproductive cell death in gastric tumor MKN45 cells with wild-type p53 and MKN28 cells with mutated p53. In addition, we examined the effects of purvalanol $\mathrm{A}$ on the expression of the anti-apoptosis proteins survivin, XIAP, Bcl- $\mathrm{X}_{\mathrm{L}}$ and BCL2.

\section{MATERIALS AND METHODS}

\section{Chemicals}

RPMI 1640 medium was purchased from Invitrogen (Carlsbad, CA). Purvalanol A and benzyloxycarbonyl-val-ala-asp-fluoromethyl-ketone (ZVAD-FMK) were obtained from Calbiochem (San Diego, CA) and dissolved in DMSO at $2 \mathrm{mM}$ and $20 \mathrm{~m} M$, respectively. Propidium iodide (PI) was purchased from Sigma Chemical Company (St. Louis, MO). RNase A was from Roche Diagnostics (Mannheim, Germany). AntiCDC2 (H-297, sc-947, Lot no. I187), anti-cyclin B1 (D-11, sc-7393, Lot no. J259), anti-WEEl (C-20, sc-325, Lot no. C301), anti-survivin (FL142, sc-10811, Lot no. E2504), anti-BAX (P-19, sc-526, Lot no. A237), anti-actin (I-19, sc-1616, Lot no. E049), donkey anti-goat IgG-HRP (sc2020, Lot no. K0504), goat anti-mouse IgG-HRP (sc-2005, Lot no. L1304), and goat anti-rabbit IgG-HRP (sc-2004, Lot no. D2805) were from Santa Cruz Biotechnology (Santa Cruz, CA). Anti-XIAP (610762, Lot no. 0000071619) was from BD Transduction Laboratories (San Jose, CA). Anti-Bcl- $\mathrm{X}_{\mathrm{L}}(010-16851$, Lot no. MNG2711) and anti-BCL2 (01316101, Lot no. RNQ2910) were from Wako (Osaka, Japan). Anti-phospho-CDC2 (no. 9111S, Lot no. 5) and anti-caspase 3 (no. 9665, Lot no. 2) were from Cell Signaling Technology (Beverly, MA). The chemiluminescence detection kit, Western Lightning ${ }^{\mathrm{TM}}$ Chemiluminescence Reagent Plus, was from Perkin Elmer (Boston, MA).

\section{Cell Culture}

Cells of the human gastric adenocarcinoma cell lines MKN45 (wildtype p53) and MKN28 (mutated p53) were grown in RPMI 1640 medium containing $10 \%$ fetal calf serum at $37^{\circ} \mathrm{C}$ in $5 \% \mathrm{CO}_{2} / 95 \%$ air. All experiments used $8 \times 10^{5}$ cells per sample. Cells were cultured for $24 \mathrm{~h}$ before starting experiments to ensure that they were in the logarithmic growth phase. At that time, cells were about $60 \%$ confluent and did not become entirely confluent before each experiment. For Western blotting, three replicates per sample were prepared to obtain sufficient amounts of cells.

\section{Treatment of Cells with Drugs and X Radiation}

$\mathrm{X}$ irradiation was performed with a Shimadzu HF-350 X-ray generator (200 kVp and $20 \mathrm{~mA}$ with a $1.0-\mathrm{mm}$ aluminum filter) at a dose rate of $3.9 \mathrm{~Gy} / \mathrm{min}$, which was determined using Fricke's chemical dosimeter. Treatments with purvalanol A and Z-VAD-FMK were carried out by adding 3.75-15 $\mu \mathrm{l}$ of $2 \mathrm{mM}$ (purvalanol A) or $20 \mathrm{mM}$ (Z-VAD-FMK) stock solution to cells in $1.5 \mathrm{ml}$ of growth medium in a 60-mm-diameter petri dish $5 \mathrm{~min}$ before $\mathrm{X}$ irradiation at $37^{\circ} \mathrm{C}$, which had the maximal effect on cell cycle inhibition (data not shown). All samples except for those treated with purvalanol A and/or Z-VAD-FMK were treated with DMSO only.

\section{Clonogenic Survival Assay}

The surviving fraction was assayed by using the plasma clot technique with platelet-poor human plasma according to the method described by Kashiwakura et al. (11). In each sample, the cells incubated for the indicated periods after $\mathrm{X}$ irradiation were collected by trypsinization and centrifugation at $1,000 \mathrm{rpm}$ for $5 \mathrm{~min}$ at $4^{\circ} \mathrm{C}$. Then the pellet was washed in $\mathrm{Ca}^{2+}$ - and $\mathrm{MG}^{2+}$-free phosphate-buffered saline PBS(-). Culture medium containing 100 to 6,000 cells $/ 0.4 \mathrm{ml}$ and $15 \%$ human platelet-poor $\mathrm{AB}$ plasma and growth factor(s) in Iscove's modified Dulbecco's medium
(Invitrogen) with $74 \mu \mathrm{g} / \mathrm{ml} \mathrm{CaCl}_{2}$ (Wako) and $0.17 \%$ bovine serum albumin (Filtron, Brooklyn, Australia) was prepared. Three replicates of medium $(0.4 \mathrm{ml})$ per dose were plated in 24-well culture plates (Corning Inc., Corning, NY) and incubated at $37^{\circ} \mathrm{C}$ in $5 \% \mathrm{CO}_{2} / 95 \%$ air for about 14 days (MKN45) and 10 days (MKN28), which were 10 times the doubling times ( $30 \mathrm{~h}$ and $22 \mathrm{~h}$ for MKN45 and MKN28 cells, respectively). Then each well was fixed twice with a 2:1 mixture of acetone and methanol for $15 \mathrm{~min}$. The plates were dried in an airflow overnight and kept at $-20^{\circ} \mathrm{C}$ until staining. For staining, the plates were removed from the freezer, returned to room temperature, stained with Giemsa stain, and scored under a microscope. Only colonies containing more than 50 cells were scored as surviving cells, and from 10 to 80 colonies were counted at each dose. After the surviving fraction at each dose was calculated with respect to the plating efficiency of the nonirradiated control, the means \pm SD of surviving fractions from three experiments were plotted to produced dose-response curves.

\section{Fluorescence Microscope Observation of Apoptotic Cells}

Cells incubated for the indicated periods after $\mathrm{X}$ irradiation were collected by centrifugation at $1,000 \mathrm{rpm}$ for $5 \mathrm{~min}$ at $4^{\circ} \mathrm{C}$. The pellet was washed in PBS(-) and fixed with $1 \%$ glutaraldehyde/PBS(-) solution. For fluorescence microscopy, the fixed cells were washed and resuspended in PBS(-). An aliquot containing $5 \times 10^{5}$ cells was stained with $40 \mu \mathrm{g} / \mathrm{ml}$ propidium iodide (PI) in $20 \mu \mathrm{l}$ of $\mathrm{PBS}(-)$ for $15 \mathrm{~min}$ in the dark. Fluorescence microscope observation was performed using an Olympus BX50 microscope with reflected-light fluorescence. Apoptosis was defined by morphological changes such as nuclear fragmentation and condensation. The fraction of apoptotic cells was calculated as the percentage of apoptotic cells relative to the total cells observed microscopically. Three independent experiments were performed.

\section{CDC2-Associated Histone H1 Phosphorylation Assay}

Measurement of cyclin-dependent CDC2-associated H1 phosphorylation was performed using a slight modification of the method described by Inanami et al. (3). Cells were lysed in lysis buffer $(50 \mathrm{~m} M$ Hepes, $\mathrm{pH}$ 7.4, $100 \mathrm{~m} M \mathrm{NaCl}, 10 \%$ glycerol, $1 \mathrm{mM} \mathrm{Na} \mathrm{P}_{2} \mathrm{O}_{7}, 1 \% \mathrm{NP}-40,50 \mathrm{~m} M$ sodium fluoride, $2 \mathrm{~m} M$ EDTA, $1 \mathrm{~m} M$ PMSF, $10 \mu \mathrm{g} / \mathrm{ml}$ aprotinin, $10 \mu \mathrm{g}$ / $\mathrm{ml}$ leupeptin, and $10 \mu \mathrm{g} / \mathrm{ml}$ pepstatin A) for $30 \mathrm{~min}$ at $4^{\circ} \mathrm{C}$. The cell lysate was centrifuged at $13,000 \mathrm{rpm}$ for $30 \mathrm{~min}$ at $4^{\circ} \mathrm{C}$. Then $400 \mu \mathrm{g}$ of protein was added to protein A-Sepharose CL-4B (Amersham Biosciences, Piscataway, NJ), preassociated with the anti-CDC2 antibody, and mixed gently overnight at $4^{\circ} \mathrm{C}$. The immunoprecipitate was washed twice with lysis buffer and twice with wash buffer ( $20 \mathrm{mM}$ Hepes, $\mathrm{pH} 7.4,10$ $\mathrm{m} M \mathrm{MgCl}_{2}, 0.5 \mathrm{~m} M$ dithiothreitol) and incubated with $20 \mu \mathrm{l}$ of wash buffer containing $3 \mu \mathrm{g}$ of histone H1 (Roche Diagnostics), $10 \mu M$ ATP, and $185 \mathrm{kBq}(5 \mu \mathrm{Ci})$ of $\left[\gamma^{-32} \mathrm{P}\right] \mathrm{ATP}(5000 \mathrm{Ci} / \mathrm{mmol}$, Amersham Biosciences) for $30 \mathrm{~min}$ at $30^{\circ} \mathrm{C}$. Each sample was mixed with $10 \mu \mathrm{l}$ of a threefold volume of Laemmli's sample buffer (187.5 $\mathrm{m} M$ Tris-HCl, $\mathrm{pH}$ $6.8,30 \%$ glycerol, $15 \% \beta$-mercaptoethanol, $4 \%$ SDS and $0.004 \%$ bromophenol blue) to stop the reaction, heated for $3 \mathrm{~min}$ at $95^{\circ} \mathrm{C}$, and subjected to SDS-PAGE. The gel was dried and analyzed with a Fuji Bioimage Analyzer BAS2500. Two independent experiments were performed.

\section{Cell Cycle Analysis by Flow Cytometry}

Cells incubated for the indicated periods after $\mathrm{X}$ irradiation were collected by centrifugation at $1,000 \mathrm{rpm}$ for $5 \mathrm{~min}$ at $4^{\circ} \mathrm{C}$. Then the pellet was suspended in $100 \mu \mathrm{l}$ of PBS(-). One microliter of $20 \mathrm{mg} / \mathrm{ml}$ RNase A in PBS(-) was added, and the suspension was incubated at $37^{\circ} \mathrm{C}$ for $30 \mathrm{~min}$ to hydrolyze RNA. After $1,000 \mathrm{rpm}$ centrifugation at $4^{\circ} \mathrm{C}$ for 5 min, the pellet was suspended in $1 \mathrm{ml}$ of PBS(-). Fifty microliters of PBS(-) containing PI at $1 \mathrm{mg} / \mathrm{ml}$ was added followed by incubation for $30 \mathrm{~min}$ in the dark for staining. The DNA content in 10,000 cells was analyzed using an EPICS XL flow cytometer (Beckman Coulter, Fullerton, CA). Three independent experiments were performed. 


\section{SDS-PAGE and Western Blotting}

Cells were collected at the indicated times after $\mathrm{X}$ irradiation, and 5 $\times 10^{6}$ cells were suspended in $75 \mu \mathrm{l}$ of lysis buffer $(20 \mathrm{~m} M$ Hepes, $\mathrm{pH}$ 7.4, $2 \mathrm{~m} M$ EGTA, $50 \mathrm{~m} M$ glycerophosphate, $1 \%$ Triton X-100, $10 \%$ glycerol, $1 \mathrm{~m} M$ PMSF, $10 \mu \mathrm{g} / \mathrm{ml}$ aprotinin, $10 \mu \mathrm{g} / \mathrm{ml}$ pepstatin A, and $10 \mu \mathrm{g} / \mathrm{ml}$ leupeptin), kept on ice for $30 \mathrm{~min}$, and sonicated twice for 30 $\mathrm{s}$ at ice-cold temperature. After centrifugation at 12,000 rpm for $30 \mathrm{~min}$ at $4^{\circ} \mathrm{C}$, a threefold volume of Laemmli's sample buffer was added to the supernatant, and it was boiled for $3 \mathrm{~min}$. Proteins were separated by SDSPAGE and transferred onto nitrocellulose membranes (Advantec Toyo, Tokyo, Japan). The membranes were probed with anti-CDC2, anti-cyclin B1, anti-WEE1, anti-survivin, anti-XIAP, anti-caspase 3 or anti-actin in TBST buffer (10 mM Tris-HCl, $0.1 \mathrm{M} \mathrm{NaCl}, 0.1 \%$ Tween-20, pH 7.4) containing 5\% nonfat skim milk, anti-phospho-CDC2 in TBST buffer containing 5\% BSA, and anti-Bcl- $\mathrm{X}_{\mathrm{L}}$, anti-BCL2 or anti-BAX in TBST buffer containing $3 \%$ nonfat skim milk. These antibodies were detected using HRP-conjugated anti-rabbit, anti-mouse or anti-goat IgG antibodies with Perkin Elmer Western Lightning ${ }^{\mathrm{TM}}$, Chemiluminescence Reagent Plus. Three independent experiments were performed. The bands were quantified by NIH Image analysis (1.63).

\section{RESULTS}

Purvalanol A Inhibits Radiation-Induced CDC2 Kinase Activity and Suppresses Accumulation in $G_{2} / M$ Phase in $X$-Irradiated Tumor Cells

Since purvalanol A was developed to target the activities of CDKs, we again confirmed that it affected the CDC2 kinase activity in MKN45 and MKN28 cells. Figure 1 shows the radiation-induced increase in $\mathrm{CDC} 2$ kinase activity as measured by the CDC2-associated histone H1 kinase assay. Since histone $\mathrm{H} 1$ is known to be a substrate for phosphorylation by CDC2, measurements of its phosphorylation level are widely recognized as cellular CDC2 kinase activity (12). The CDC2 kinase activity increased with time up to $24 \mathrm{~h}$ and then appeared to level off in MKN45 cells, whereas it increased with time up to $36 \mathrm{~h}$ in MKN28 cells (Fig. 1A and B, upper panel). Treatment of irradiated cells with purvalanol A suppressed the radiation-induced increase in CDC2 kinase activity (Fig. 1A and B, lower panel). This result was in accord with a previous report (10).

To study the effects of purvalanol A on radiation-induced cell cycle checkpoints and apoptosis, flow cytometry analysis was performed using MKN45 and MKN28 cells (Fig. 2 ). The profile of untreated cells was unchanged through $24 \mathrm{~h}$ (Fig. 2A). When cells were exposed to $20 \mathrm{~Gy}$ of $\mathrm{X}$ rays and incubated for $24 \mathrm{~h}$, the flow cytometry profile showed a marked increase in the $\mathrm{G}_{2} / \mathrm{M}$ fraction but not in the sub- $\mathrm{G}_{1}$ fraction, suggesting that radiation-induced $\mathrm{G}_{2} / \mathrm{M}$ arrest occurred. Cotreatment of cells with purvalanol A and $X$ rays resulted in a decrease in the $G_{2} / M$ fraction and an increase in the sub- $\mathrm{G}_{1}$ fraction. In purvalanol A-treated cells, the $G_{1}$ fraction was slightly decreased but the $S$ and $\mathrm{G}_{2} / \mathrm{M}$ fractions leveled off, indicating the inhibition of $\mathrm{G}_{1^{-}}$ to S-phase progression. This phenomenon was in accord with a previous report (13). Then an increase in the sub- $\mathrm{G}_{1}$ fraction was observed, showing the toxicity of $20 \mu M$ purvalanol A. The increase of the sub- $\mathrm{G}_{1}$ fraction in purvalanol
A) MKN45

untreated
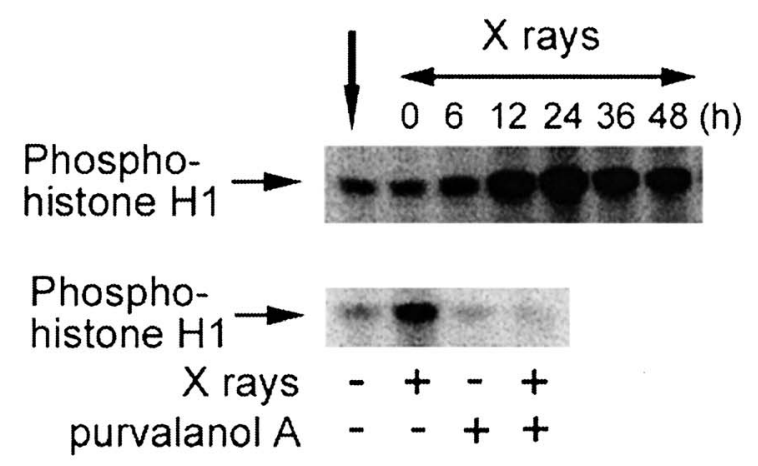

\section{B) $M K N 28$}

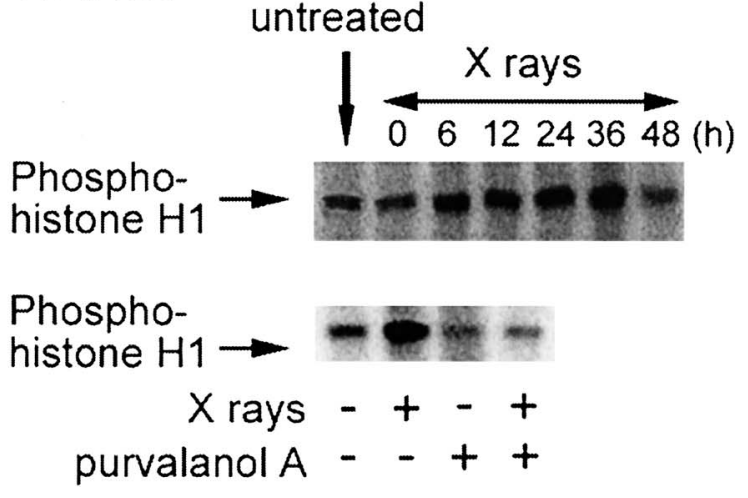

FIG. 1. CDC2 kinase assay of MKN45 cells (panel A) and MKN28 cells (panel B) exposed to $20 \mathrm{~Gy}$ of $\mathrm{X}$ rays at the indicated times (upper panel). Effect of $20 \mu M$ purvalanol A on CDC2 kinase activity at $24 \mathrm{~h}$ after 20 Gy of $\mathrm{X}$ irradiation (lower panel).

A-treated cells exposed to 20 Gy of $\mathrm{X}$ rays was significantly different from that of treatment with purvalanol A alone [sub- $\mathrm{G}_{1}$ fraction at $24 \mathrm{~h}: 22.7 \pm 0.9 \%$ (MKN45) and $24.0 \pm 1.0 \%$ (MKN28) with purvalanol A only, and 50.6 $\pm 0.8 \%(\mathrm{MKN} 45)$ and $40.4 \pm 0.1 \%(\mathrm{MKN} 28)$ in purvalanol A-treated cells exposed to $20 \mathrm{~Gy}$ of $\mathrm{X}$ rays, $P<0.01$ by Student's $t$ test]. Observation of the time course of the cell cycle confirmed that $\mathrm{X}$ radiation alone increased the $\mathrm{G}_{2} / \mathrm{M}$ fraction and purvalanol $A$ increased the sub- $\mathrm{G}_{1}$ fraction (fraction of apoptotic cells), whereas it reduced the $\mathrm{G}_{2} /$ $\mathrm{M}$ fraction. These results suggested that purvalanol $\mathrm{A}$ inhibited radiation-induced CDC 2 kinase activity and reduced accumulation of $\mathrm{X}$-irradiated cells in $\mathrm{G}_{2} / \mathrm{M}$.

\section{Purvalanol A Inhibits Activation of Radiation-Induced $G_{2} / M$ Checkpoint-Related Proteins}

To examine the effects of $X$ rays with and without purvalanol $A$ on regulatory proteins for the $G_{2} / M$ phase, the expression of phospho-CDC2, CDC2, WEE1 and cyclin B1 was examined. Figure $3 \mathrm{~A}$ shows the results for $\mathrm{X}$-irradiated cells. Accumulation of cyclin B1 and phospho-CDC2, 


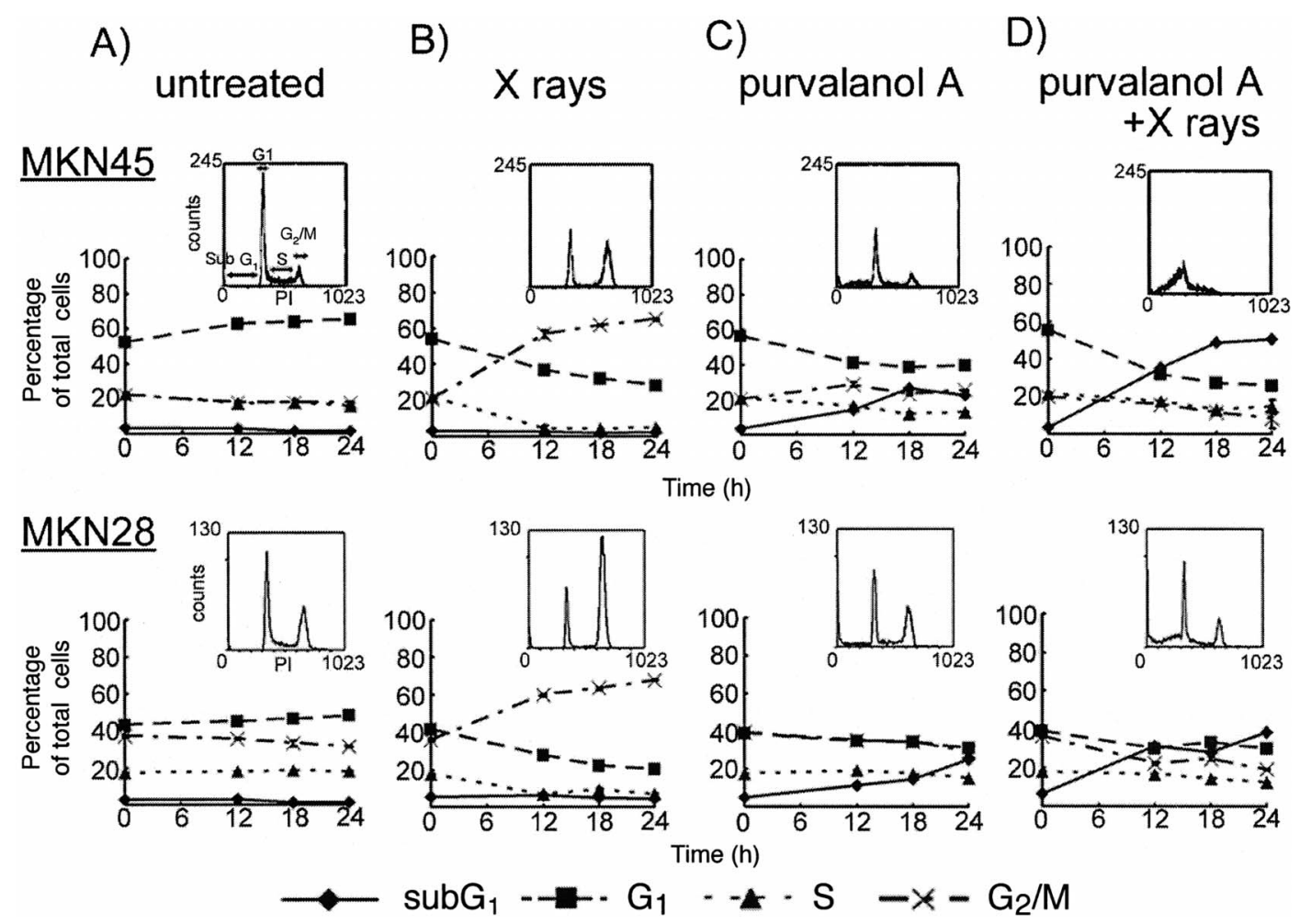

FIG. 2. Flow cytometry profiles of cell cycle distribution without treatment (panel A), with 20 Gy of $X$ rays (panel B), with $20 \mu M$ purvalanol A (panel C), and with 20 Gy of X rays plus $20 \mu M$ purvalanol A (panel D). Profiles were taken at $0,12,18$ and $24 \mathrm{~h}$ after treatments. Data are expressed as means \pm SD for three experiments. Representative cell cycle distribution patterns at $24 \mathrm{~h}$ are shown in the insets. The $X$ and $Y$ axes indicate the DNA content and the number of cells, respectively.

which are important regulating molecules for the cell cycle in the $\mathrm{G}_{2} / \mathrm{M}$ phase, occurred even though the expression levels of CDC2 and WEE1 were constant. The treatment with purvalanol A suppressed the expression of phosphoCDC2, WEE1 and cyclin B1 not only in X-irradiated cells but also in unirradiated cells compared with that shown in Fig. 3A (Fig. 3C). The change in the cell cycle distribution induced by purvalanol A alone, as shown in Fig. $2 \mathrm{C}$, might have been due to the decreased responses in the expression of these cell cycle-related proteins. Quantitative analysis of these bands showed a significant difference between X-irradiated cells and purvalanol A-treated cells exposed to $\mathrm{X}$ rays at $24 \mathrm{~h}$ (Fig. 3D, F, G).

\section{Purvalanol A Enhances Radiation-Induced Cell Death in MKN45 and MKN28 Cells}

As shown in Fig. 2, cotreatment of cells with purvalanol $A$ and $X$ rays increased the sub- $G_{1}$ fraction, suggesting the induction of apoptosis. Therefore, we examined the effects of $\mathrm{X}$ rays with and without purvalanol $\mathrm{A}$ on apoptosis by morphological evaluation. Figure 4A shows fluorescence microscope observations of morphological changes characteristic of apoptosis in nuclei stained with propidium iodide, including DNA fragmentation and chromatin condensation. X irradiation with a dose of 20 Gy induced no ap- optosis. When cells were treated with purvalanol A after X irradiation, typical morphological alterations characteristic of apoptosis were observed (white arrows in the fourth panel of Fig. 4A). Quantitative measurements of apoptotic cells done with fluorescence microscopy revealed that, starting at $10 \mu M$ purvalanol $\mathrm{A}$, apoptosis was induced in a dosedependent manner in X-irradiated cells (Fig. 4B). In cells treated with $15 \mu M$ purvalanol $\mathrm{A}$, the number of apoptotic cells increased as a function of the X-ray dose in the range from 2.5 Gy to 20 Gy (Fig. 4C). Figure 4D shows that the broad-spectrum caspase inhibitor Z-VAD-FMK almost completely inhibited the induction of apoptosis. These results suggested that the induction of apoptosis by cotreatment of cells with purvalanol A and X rays was dependent on the activity of caspase. In addition, it was also observed that Z-VAD-FMK inhibited purvalanol A-induced apoptosis (data not shown). Similar observations were obtained for MKN28 cells (Fig. 4E). Furthermore, to evaluate whether purvalanol A enhanced radiation-induced reproductive cell death, the colony-forming ability of the cells was examined. About $50 \%$ of MKN45 cells and 30\% of MKN28 cells survived at the concentration of $15 \mu M$ purvalanol A. Even after correction of the surviving fraction for this toxicity, significant sensitization in clonogenic survivals was observed (Fig. 4F and G). No enhancement of radiation- 


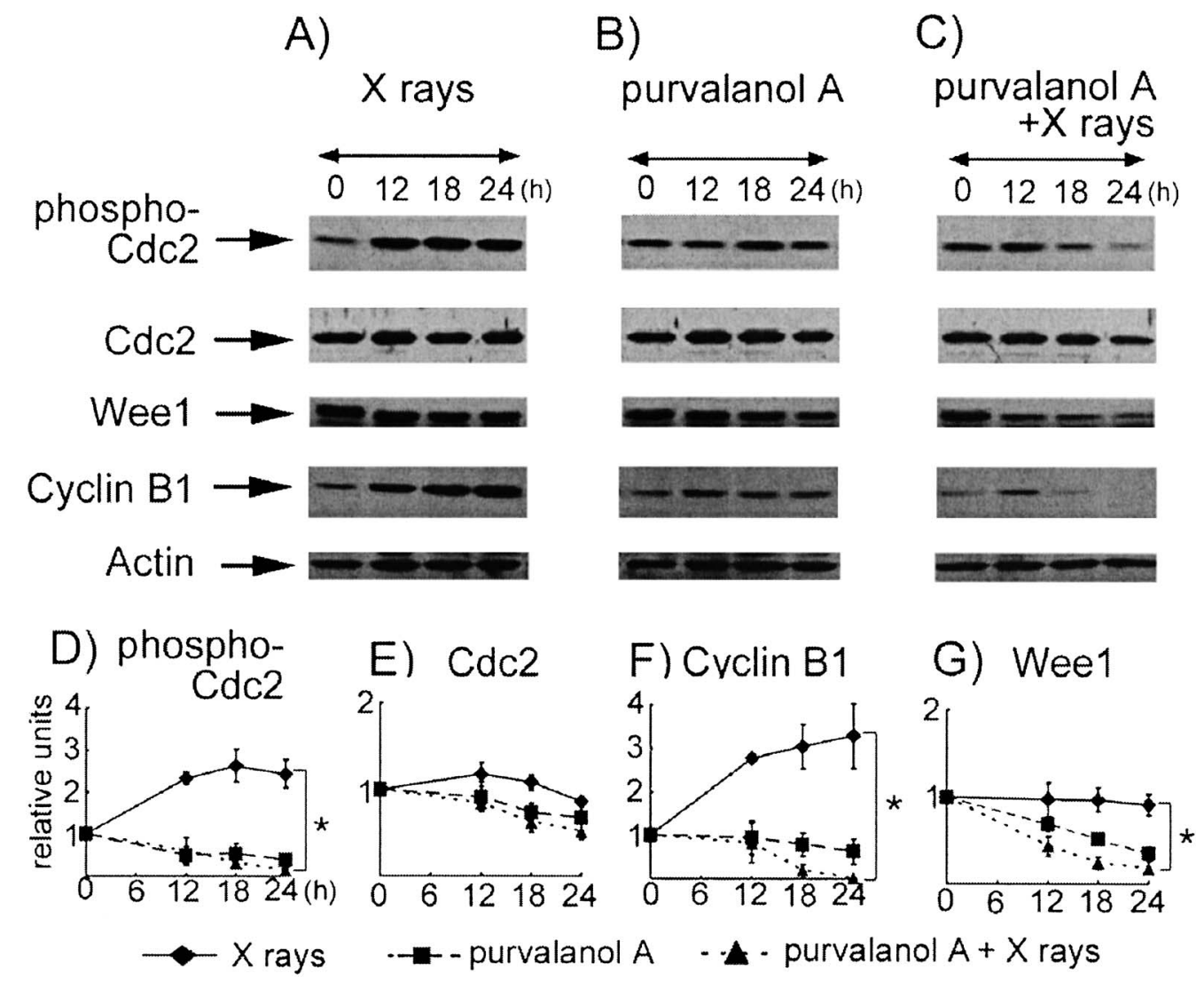

FIG. 3. Western blot analysis of the expression of phospho-CDC2, CDC2, WEE1 and cyclin B1 using corresponding antibodies. MKN45 cells treated with 20 Gy of X rays (panel A), $20 \mu M$ purvalanol A (panel B), and 20 Gy of X rays and $20 \mu M$ purvalanol A (panel C) were incubated for $0,12,18$ and $24 \mathrm{~h}$. Actin in each sample was employed as a standard. Quantification of bands of phospho-CDC2 (panel D), CDC2 (panel E), WEE1 (panel F) and cyclin B1 (panel G) was performed using NIH Image analysis normalized to actin. Data are expressed as means \pm SE for three experiments. Treatment of cells with $20 \mathrm{~Gy}$ of $\mathrm{X}$ rays and that with $20 \mathrm{~Gy}$ of $\mathrm{X}$ rays and $20 \mu M$ purvalanol $\mathrm{A}$ at $24 \mathrm{~h}$ were compared by Student's $t$ test, $* P<0.05$.

induced reproductive cell death by $10 \mu M$ purvalanol A was observed (data not shown). Activation of caspase 3, the key molecule in the induction of apoptosis, was also examined in MKN45 and MKN28 cells as shown in Fig. 5. The activation of caspase 3 is known to be achieved through the proteolytic processes of procaspase 3 by upstream caspase 8 or caspase 9 (14). The active fragments of caspase 3 (p17) were not detected after the treatment with $\mathrm{X}$ rays alone, whereas faint bands due to active fragments were found after the treatment with purvalanol A alone. Large amounts of the active fragments were observed in X-irradiated cells treated with purvalanol A (Fig. 5A). Quantitative analysis of these bands showed a significant difference between purvalanol A-treated cells and purvalanol A-treated cells exposed to X rays (Fig. 5B), and the amounts of active fragments in purvalanol A-treated cells exposed to X rays were 4.3-fold in MKN45 and 7.2fold in MKN28 compared with those of purvalanol A-treated cells, respectively. These results suggested that the enhancement of purvalnaol A-induced apoptosis in X-irradiated gastric tumor cells could be explained by the increase in active caspase 3 .

\section{Purvalanol A Inhibits the Expression of Radiation- Induced Anti-apoptosis Proteins}

To identify the molecules responsible for radiation-induced apoptosis in the presence of purvalanol A, the expression of anti-apoptosis proteins was examined in MKN45 cells. Western blot analysis of survivin, XIAP, Bcl- $X_{L}$ and BCL2 is shown in Fig. 6. In the Western blots obtained from cells exposed to $\mathrm{X}$ rays alone, the expression of survivin and XIAP was almost unchanged (Fig. $6 \mathrm{~A}$ ), whereas expression of $\mathrm{Bcl}-\mathrm{X}_{\mathrm{L}}$ and BCL2 was increased. Treatment with purvalanol A suppressed not only the basal expression of survivin, XIAP, Bcl- $\mathrm{X}_{\mathrm{L}}$ and BCL2 (Fig. 6B) but also the radiation-induced increases in the expression of all proteins (Fig. 6C). On the other hand, the expression of BAX, a known pro-apoptosis protein, was almost unchanged after $\mathrm{X}$ irradiation but was slightly decreased by the treatment with purvalanol A. These data indicated that the decrease in expression of anti-apoptosis proteins induced by purvalanol A occurred irrespective of the treatment with $\mathrm{X}$ radiation. Moreover, down-regulation of the expression of survivin and $\mathrm{Bcl}-\mathrm{X}_{\mathrm{L}}$ was also ob- 
A)

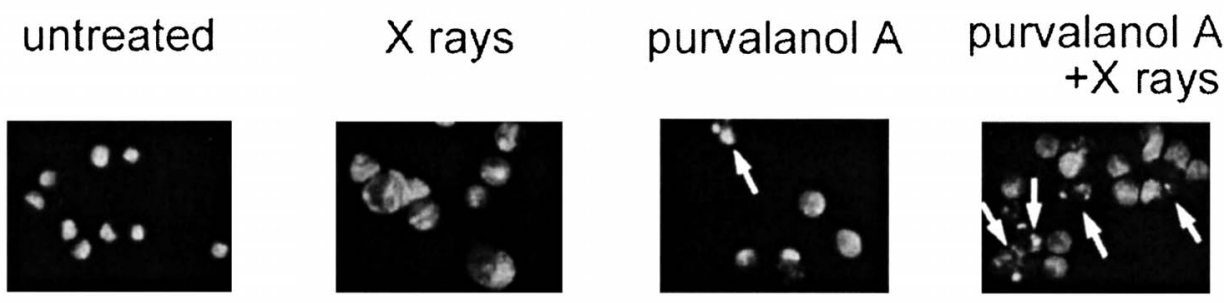

B)

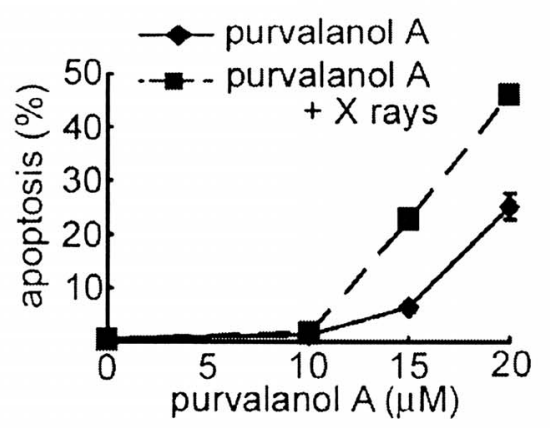

C)

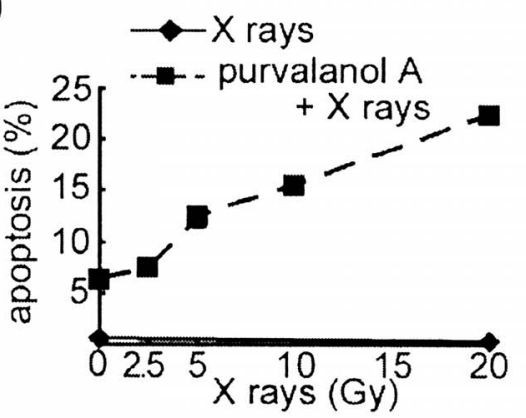

D) $\mathrm{MKN} 45$

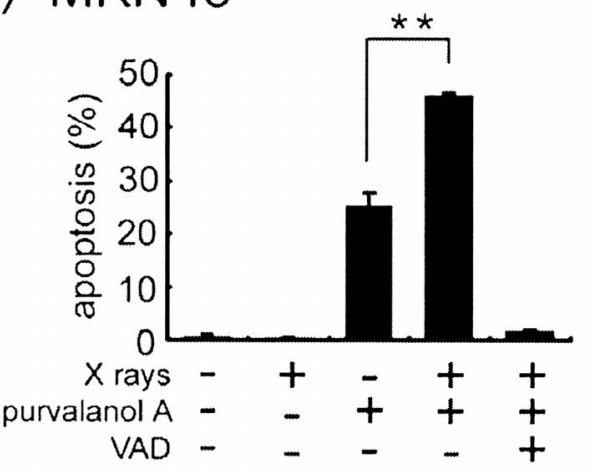

E) MKN28

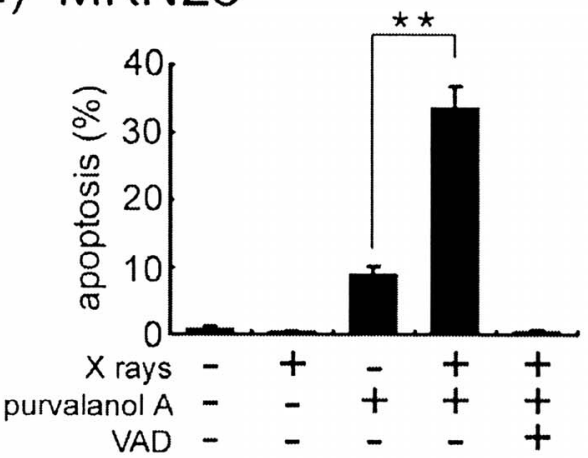

\section{F) MKN45}

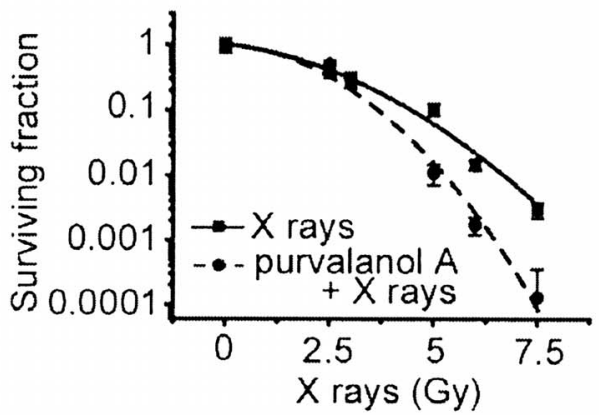

G) MKN28

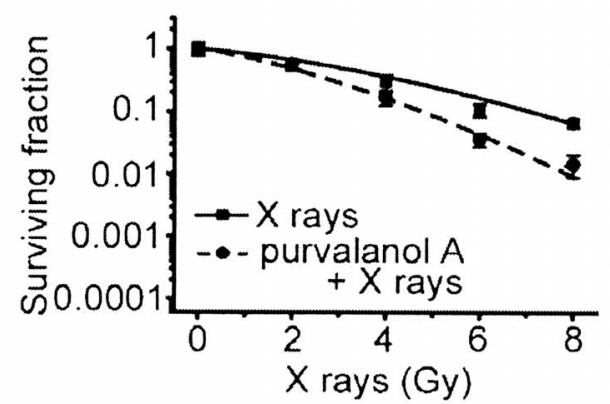

FIG. 4. Panel A: Fluorescence microscopy photographs of nuclei of untreated cells and cells treated with 20 Gy of $\mathrm{X}$ rays, purvalanol A $(20 \mu M)$, and purvalanol A $(20 \mu M)$ plus $\mathrm{X}$ rays $(20 \mathrm{~Gy})$ at $24 \mathrm{~h}$. White arrows indicate morphological changes characteristic of apoptosis. Panel B: Induction of apoptosis (\%) in cells treated with 20 Gy of $\mathrm{X}$ rays and the indicated concentration of purvalanol $\mathrm{A}$ and (panel $\mathrm{C}$ ) with $15 \mu M$ purvalanol A plus the indicated dose of $\mathrm{X}$ rays. In each case, at least 300 cells were evaluated for apoptosis. Data are expressed as means \pm SE for three experiments. Induction of apoptosis (\%) in (panel D) MKN45 and (panel E) MKN28 cells treated with 20 Gy of X rays, $20 \mu M$ purvalanol A, $20 \mu M$ purvalanol A and 20 Gy of X rays, and with $20 \mu M$ purvalanol A, 20 Gy of $\mathrm{X}$ rays and $50 \mu M \mathrm{Z}$-VAD-FMK. Data are expressed as means $\pm \mathrm{SE}$ for three experiments. In each case, at least 300 cells were evaluated for apoptosis. ${ }^{*} P<0.01$ by Student's $t$ test. Dose-response curves of $\mathrm{X}$-irradiated (panel F) MKN45 and (panel G) MKN28 cells: (ם) X irradiation and (O) X irradiation in the presence of $15 \mu M$ purvalanol A for $24 \mathrm{~h}$ as measured by colony formation. Data are expressed as means \pm SD for three experiments. 


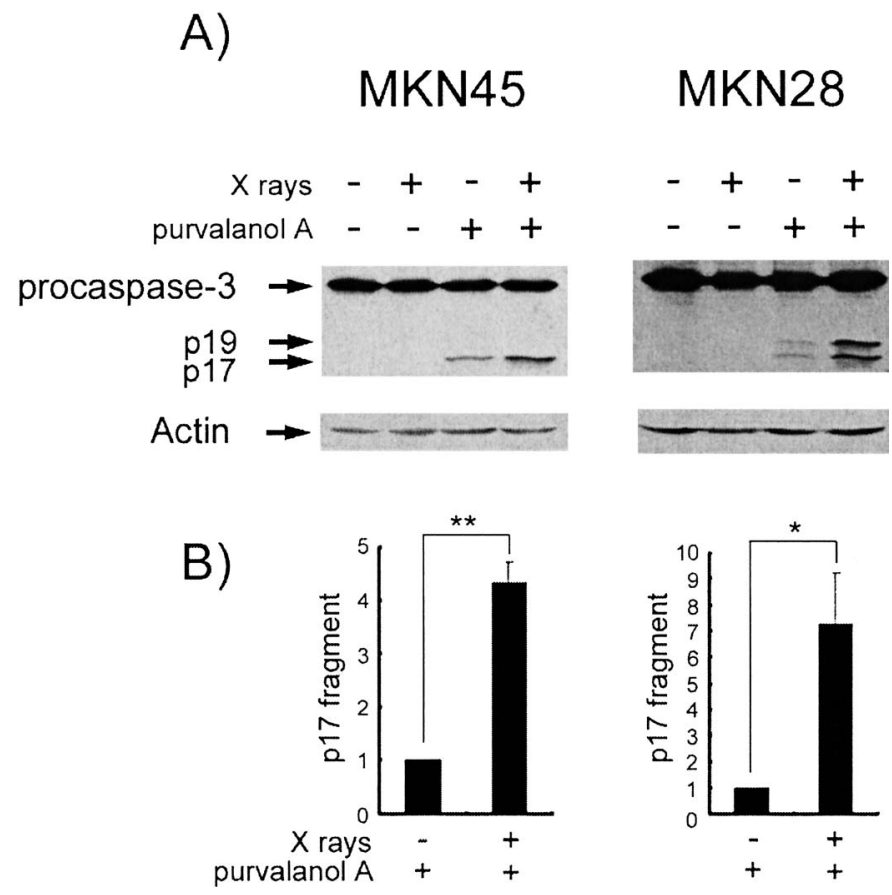

FIG. 5. Panel A: Western blot analysis of the expression of caspase 3 in MKN45 (left panel) and MKN28 (right panel) cells treated with 20 Gy of X rays, $20 \mu M$ purvalanol A, or $20 \mu M$ purvalanol A plus $20 \mathrm{~Gy}$ of $\mathrm{X}$ rays at $24 \mathrm{~h}$. Actin in each sample was employed as a standard. Panel B: Quantification of bands of active caspase 3 (p17) was performed using NIH Image analysis normalized to actin. Data are expressed as means \pm SE for three experiments. Treatment of cells with $20 \mu M$ purvalanol A and with 20 Gy of $\mathrm{X}$ rays plus $20 \mu M$ purvalanol A were compared by Student's $t$ test; $* P<0.05$ and $* * P<0.01$.

served in X-irradiated MKN28 cells in the presence of purvalanol A (Fig. 6I-K). Quantitative analysis showed that levels of these anti-apoptosis proteins in purvalanol A-treated cells with and without $\mathrm{X}$ rays were significantly lower than those in cells exposed to $\mathrm{X}$ rays alone (Fig. 6D-G, L-M).

\section{DISCUSSION}

In the present study, radiation-induced up-regulation of CDC2 kinase activity was shown to be inhibited by treatment with purvalanol A (Fig. 1). Gray et al. tested the inhibitory effect of purvalanol A against the activities of 22 human kinases in a cell-free system and found that CDC2 kinase activity was strongly inhibited at a low concentration of this drug $\left(\mathrm{IC}_{50} ; 4 \mathrm{nM}\right)(8)$, indicating its high selectivity. We confirmed this characteristic of purvalanol $\mathrm{A}$ in a cellular system using MKN45 cells by observing that treatment of cells with $20 \mu M$ purvalanol A completely inhibited the radiation-induced increase in the activity of $\mathrm{CDC} 2$ and the expression of phospho-CDC2 and cyclin B1 (Figs. 1 and 3) in the $\mathrm{G}_{2} / \mathrm{M}$ fraction (Fig. 2) and produced an increase in the sub- $G_{1}$ fraction. From these results, it was concluded that purvalanol A had strong inhibitory ef-
MKN45

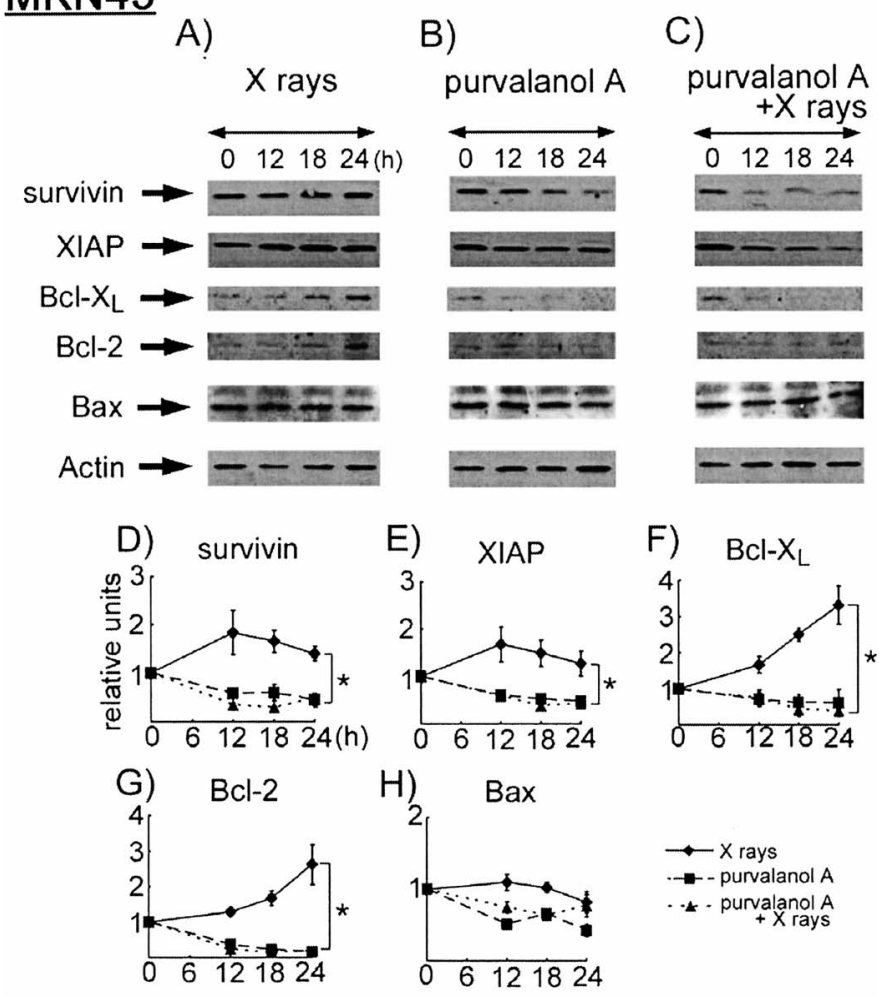

MKN28

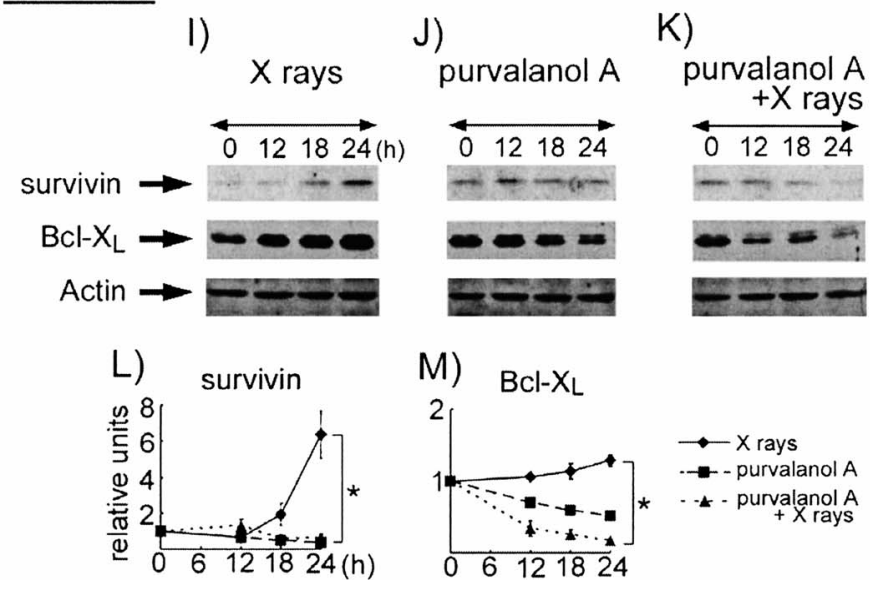

FIG. 6. Panels A-H: Western blot analysis of the expression of survivin, XIAP, Bcl- $X_{\mathrm{L}}, \mathrm{BCL} 2$ and BAX. MKN45 cells treated with 20 Gy of $\mathrm{X}$ rays (panel A), $20 \mu M$ purvalanol A (panel B), and 20 Gy of $\mathrm{X}$ rays plus $20 \mu M$ purvalanol $\mathrm{A}$ (panel $\mathrm{C}$ ) were incubated for $0,12,18$ and $24 \mathrm{~h}$. Actin was used as a standard in each sample. Quantification of bands of survivin (panel D), XIAP (panel E), Bcl-X $\mathrm{L}_{\mathrm{L}}$ (panel F), BCL2 (panel G) and BAX (panel H) was performed using NIH Image analysis normalized to actin. Panels I-M: Western blot analysis of the expression of survivin and Bcl- $\mathrm{X}_{\mathrm{L}}$. MKN28 cells treated with $20 \mathrm{~Gy}$ of $\mathrm{X}$ rays (panel I), $20 \mu M$ purvalanol $\mathrm{A}$ (panel $\mathrm{J}$ ) and $20 \mathrm{~Gy}$ of $\mathrm{X}$ rays and $20 \mu M$ purvalanol A (panel K) were incubated for $0,12,18$ and $24 \mathrm{~h}$. Actin was used as a standard in each sample. Quantification of bands of survivin (panel L) and Bcl- $\mathrm{X}_{\mathrm{L}}$ (panel $\mathrm{M}$ ) was performed using NIH Image analysis normalized to actin. Data are expressed as means \pm SE for three experiments. Treatment of cells with $20 \mathrm{~Gy}$ of X rays and that with $20 \mathrm{~Gy}$ of $\mathrm{X}$ rays plus $20 \mu M$ purvalanol A at $24 \mathrm{~h}$ were compared by Student's $t$ test, $* P<0.05$. 
fects against radiation-induced activation of $\mathrm{CDC} 2$ and the $\mathrm{G}_{2} / \mathrm{M}$ checkpoint.

Interestingly, the enhancement of radiation-induced apoptosis by purvalanol A occurred in a p53-independent manner, because the enhancement was observed in both p53-wild MKN45 cells and p53-mutated MKN28 cells. In addition, sensitization was observed in the radiation-induced loss of clonogenicity. This is the first report that purvalanol A enhances high-dose radiation-induced cell death through the inhibition of radiation-induced $\mathrm{CDC} 2$ kinase activity (Figs. 1 and 4). For sensitization to cell killing in tumor cells and tissues exposed to ionizing radiation, treatments combined with a pharmacological agent with the ability to abrogate the $\mathrm{G}_{2} / \mathrm{M}$ checkpoint have been of interest. UCN-01 and caffeine have been shown to be able to enhance radiation-induced cell killing by inhibition of kinases such as ATM, ataxia telangiectasia mutated and RAD3-related (ATR), and CHK1 exists in the upstream of CDC2 (15-18). Palayoor et al. examined the effects of several xanthine derivatives on the radiation-induced $\mathrm{G}_{2} / \mathrm{M}$ checkpoint and apoptosis and found that caffeine, theobromine, theophylline and 2-aminopurine abrogated the checkpoint and enhanced the degree of apoptosis in EL4 murine T-lymphoma cells (19). In addition, caffeine and UCN-01 efficiently abrogated radiation-induced $\mathrm{G}_{2} / \mathrm{M}$ arrest and induced mitochondrial activation and the release of cytochrome c and Smac/Diablo, which are two mitochondrionderived pro-apoptosis factors required for the activation of the intrinsic death pathway, in MCF-7 cells lacking caspase 3 expression (20). Our present experiments showed that pharmacological inhibition of the activity of $\mathrm{CDC} 2$, which is considered a downstream signaling molecule of ATM, ATR or CHK1, also induced inhibition of the $\mathrm{G}_{2} / \mathrm{M}$ checkpoint and enhanced the induction of apoptosis in gastric tumor cells exposed to $\mathrm{X}$ rays, suggesting that the radiationinduced activation of CDC2 up-regulated the anti-apoptosis system. Evaluation of the expression of anti-apoptosis proteins in MKN45 cells exposed to $\mathrm{X}$ rays in the presence or absence of purvalanol A led us to postulate that CDC2 could regulate the expression of survivin and XIAP, as shown in Fig. 6. Activated $\mathrm{CDC} 2$ has been reported to phosphorylate survivin at $\mathrm{Thr} 34$, resulting in resistance to the ubiquitin-proteasome pathway $(10,21)$. This fact prompted us to speculate that the inhibition of radiationinduced $\mathrm{CDC} 2$ kinase activity by purvalanol $\mathrm{A}$ shortened the lifetime of survivin. It has also been reported that a dominant-negative CDC2 mutant down-regulates the expression of XIAP (22). Survivin and XIAP are reported to be inhibitors of apoptosis protein (IAP) with baculovirus IAP repeat (BIR) domains and to suppress apoptosis by interacting with both initiator and effector caspases and then inhibiting their enzymatic activities $(23,24)$. Survivin was also found to be expressed intensely in the $\mathrm{G}_{2} / \mathrm{M}$ phase (23). Recently, survivin and XIAP have been focused on as molecular targets for cancer therapy, since the basal expression levels of survivin and XIAP proteins are elevated in many cancer cell lines, and their down-regulation makes cancer cells more sensitive to chemotherapeutic drugs (25). The present experiments showed that purvalanol A downregulated the IAP and anti-apoptosis BCL2 families, suggesting that it has potential for clinical use, though more low-dose experiments should be done.

Inhibition of ERK1/2 activity was reported to induce down-regulation of the expression of anti-apoptosis homologs Bcl- $X_{\mathrm{L}}, \mathrm{BCL} 2$ and MCL1 in pancreatic tumor MIA PaCa-2 cells (26). Therefore, the down-regulation of the expression of Bcl- $\mathrm{X}_{\mathrm{L}}$ and BCL2 shown in Fig. 6C may be explained by a nonspecific inhibitory effect of purvalanol A on ERK1/2 activity. However, treatment of X-irradiated MKN45 cells with an ERK1/2 inhibitor, PD98059, did not affect the increase in the induction of apoptosis (data not shown). This indicated that the ERK signaling pathway was not associated with the enhancement of radiation-induced cell killing by purvalanol $\mathrm{A}$ in the tumor cells used in the present experiments. As a possible mechanism for the suppression of anti-apoptosis proteins by purvalanol A, the inhibition of radiation-induced CDC2 kinase activity by purvalanol A may attenuate the transcription factors for these anti-apoptosis proteins, because Bhonde et al. showed that the inhibition of cyclin-dependent kinase by a high dose of $\mathrm{UCN}-01$ induced apoptosis and the down-regulation of Bcl$\mathrm{X}_{\mathrm{L}}$ in colon carcinoma cell lines SW48 and HT-29 through inhibition of STAT3 and NF-кB (27).

As demonstrated in Fig. 6, the expression levels of antiapoptosis proteins, i.e., survivin, XIAP, Bcl- $\mathrm{X}_{\mathrm{L}}$ and BCL2, with purvalanol A alone were similar to those with purvalanol $\mathrm{A}$ and $\mathrm{X}$ rays. On the other hand, $\mathrm{X}$ radiation alone induced increases of the expression of $\mathrm{Bcl}-\mathrm{X}_{\mathrm{L}}$ and BCL2 but did not significantly influence the expression of survivin or XIAP. Consequently, $\mathrm{X}$ radiation alone induced no apoptosis, as shown in Fig. 4. If radiation-induced DNA damage or membrane damage could initiate the signal transduction pathways for apoptosis, the radiation-induced up-regulation of the expression of Bcl- $\mathrm{X}_{\mathrm{L}}$ and BCL2 shown in Fig. 6 might inhibit unknown intermediate molecules to lead to apoptosis. At this stage, we cannot accurately explain how the treatment with purvalanol A enhanced apoptosis in the tumor cells exposed to $\mathrm{X}$ rays, as shown in Fig. 4. However, down-regulation of anti-apoptosis proteins in the presence of purvalanol A may lead to abrogation of their anti-apoptosis functions induced by $\mathrm{X}$ radiation, followed by enhancement of apoptosis. In fact, the formation of active fragments of caspase 3 (p17) was not induced by $\mathrm{X}$ radiation alone, but large amounts of these active fragments appeared when the anti-apoptosis proteins in cells exposed to $\mathrm{X}$ rays were down-regulated by the treatment with purvalanol A, as shown in Fig. 5. This fact strongly suggested that the treatment with purvalanol A released the inhibitory machinery against caspase 3-dependent signal transduction pathways leading to apoptosis in X-irradiated tumor cells.

In summary, the CDK inhibitor purvalanol A was shown 
to efficiently inhibit radiation-induced CDC2 kinase activity and the expression of regulatory proteins of the $\mathrm{G}_{2} / \mathrm{M}$ phase, which were related to the $\mathrm{G}_{2} / \mathrm{M}$ checkpoint. Furthermore, the treatment with purvalanol A resulted in a significant increase in radiation-induced cell death. These data suggest that the inhibition of radiation-induced CDC2 kinase activity could be a clinical target for cancer radiotherapy.

\section{ACKNOWLEDGMENTS}

This work was supported in part by Grants-in-Aid for Basic Scientific Research from the Ministry of Education, Culture, Sports, Science and Technology of Japan [No. 15380199 (OI), No. 14636111 (OI) and No. 15025202 (MK) and the Akiyama Foundation (MK)].

Received: March 14, 2006; accepted: November 17, 2006

\section{REFERENCES}

1. T. S. Lawrence, A. W. Blackstock and C. McGinn, The mechanism of action of radiosensitization of conventional chemotherapeutic agents. Semin. Radiat. Oncol. 13, 13-21 (2003).

2. S. Tabata, M. Tanaka, Y. Endo, T. Obata, A. Matsuda and T. Sasaki, Anti-tumor mechanisms of 3'-ethynyluridine and 3'-ethynylcytidine as RNA synthesis inhibitors: Development and characterization of 3'-ethynyluridine-resistant cells. Cancer Lett. 116, 225-231 (1997).

3. O. Inanami, D. Iizuka, A. Iwahara, T. Yamamori, Y. Kon, T. Asanuma, A. Matsuda, I. Kashiwakura, K. Kitazato and M. Kuwabara, A novel anticancer ribonucleoside, 1-(3-C-ethynyl-beta-d-ribo-pentofuranosyl)cytosine, enhances radiation-induced cell death in tumor cells. Radiat. Res. 162, 635-645 (2004).

4. D. Iizuka, O. Inanami, A. Matsuda, I. Kashiwakura, T. Asanuma and M. Kuwabara, X irradiation induces the proapoptotic state independent of the loss of clonogenic ability in Chinese hamster V79 cells. Radiat. Res. 164, 36-44 (2005).

5. D. S. O'Connor, D. Grossman, J. Plescia, F. Li, H. Zhang, A. Villa, S. Tognin, P. C. Marchisio and D. C. Altieri, Regulation of apoptosis at cell division by $\mathrm{p} 34 \mathrm{cdc} 2$ phosphorylation of survivin. Proc. Natl. Acad. Sci. USA 97, 13103-13107 (2000).

6. M. Mesri, N. R. Wall, J. Li, R. W. Kim and D. C. Altieri, Cancer gene therapy using a survivin mutant adenovirus. J. Clin. Invest. 108, 981-990 (2001).

7. N. R. Wall, D. S. O'Connor, J. Plescia, Y. Pommier and D. C. Altieri, Suppression of survivin phosphorylation on Thr34 by flavopiridol enhances tumor cell apoptosis. Cancer Res. 63, 230-235 (2003).

8. N. S. Gray, L. Wodicka, A. M. Thunnissen, T. C. Norman, S. Kwon, F. H. Espinoza, D. O. Morgan, G. Barnes, S. LeClerc and P. G. Schultz, Exploiting chemical libraries, structure, and genomics in the search for kinase inhibitors. Science 281, 533-538 (1998).

9. I. R. Hardcastle, B. T. Golding and R. J. Griffin, Designing inhibitors of cyclin-dependent kinases. Annu. Rev. Pharmacol. Toxicol. 42, 325-348 (2002).

10. D. S. O'Connor, N. R. Wall, A. C. Porter and D. C. Altieri, A p34(cdc2) survival checkpoint in cancer. Cancer Cell 2, 43-54 (2002).

11. I. Kashiwakura, M. Murakami, O. Inanami, Y. Hayase, T. A. Taka- hashi, M. Kuwabara and Y. Takagi, Effects of amifostine on the proliferation and differentiation of megakaryocytic progenitor cells. Eur. J. Pharmacol. 437, 19-25 (2002).

12. D. Arion, L. Meijer, L. Brizuela and D. Beach, cdc2 is a component of the M phase-specific histone H1 kinase: Evidence for identity with MPF. Cell 55, 371-378 (1988).

13. N. Villerbu, A. M. Gaben, G. Redeuilh and J. Mester, Cellular effects of purvalanol A: A specific inhibitor of cyclin-dependent kinase activities. Int. J. Cancer 97, 761-769 (2002).

14. G. M. Cohen, Caspases: The executioners of apoptosis. Biochem. J. 326, 1-16 (1997).

15. E. C. Busby, D. F. Leistritz, R. T. Abraham, L. M. Karnitz and J. N. Sarkaria, The radiosensitizing agent 7-hydroxystaurosporine (UCN01) inhibits the DNA damage checkpoint kinase hChk1. Cancer Res. 60, 2108-2112 (2000).

16. L. C. Playle, D. J. Hicks, D. Qualtrough and C. Paraskeva, Abrogation of the radiation-induced $\mathrm{G}_{2}$ checkpoint by the staurosporine derivative UCN-01 is associated with radiosensitisation in a subset of colorectal tumour cell lines. Br. J. Cancer 87, 352-358 (2002).

17. M. Bache, S. Pigorsch, J. Dunst, P. Wurl, A. Meye, F. Bartel, H. Schmidt, F. W. Rath and H. Taubert, Loss of $\mathrm{G}_{2} / \mathrm{M}$ arrest correlates with radiosensitization in two human sarcoma cell lines with mutant p53. Int. J. Cancer 96, 110-117 (2001).

18. J. N. Sarkaria, E. C. Busby, R. S. Tibbetts, P. Roos, Y. Taya, L. M. Karnitz and R. T. Abraham, Inhibition of ATM and ATR kinase activities by the radiosensitizing agent, caffeine. Cancer Res. 59, 43754382 (1999).

19. S. T. Palayoor, R. M. Macklis, E. A. Bump and C. N. Coleman, Modulation of radiation-induced apoptosis and $\mathrm{G}_{2} / \mathrm{M}$ block in murine T-lymphoma cells. Radiat. Res. 141, 235-243 (1995).

20. F. Essmann, I. H. Engels, G. Totzke, K. Schulze-Osthoff and R. U. Janicke, Apoptosis resistance of MCF-7 breast carcinoma cells to ionizing radiation is independent of p53 and cell cycle control but caused by the lack of caspase- 3 and a caffeine-inhibitable event. Cancer Res. 64, 7065-7072 (2004).

21. J. Zhao, T. Tenev, L. M. Martins, J. Downward and N. R. Lemoine, The ubiquitin-proteasome pathway regulates survivin degradation in a cell cycle-dependent manner. J. Cell Sci. 113, 4363-4371 (2000).

22. E. H. Kim, S. U. Kim, D. Y. Shin and K. S. Choi, Roscovitine sensitizes glioma cells to TRAIL-mediated apoptosis by downregulation of survivin and XIAP. Oncogene 23, 446-456 (2004).

23. D. C. Altieri, The molecular basis and potential role of survivin in cancer diagnosis and therapy. Trends Mol. Med. 7, 542-547 (2001).

24. C. W. Wright and C. S. Duckett, Reawakening the cellular death program in neoplasia through the therapeutic blockade of IAP function. J. Clin. Invest. 115, 2673-2678 (2005).

25. L. Yang, Z. Cao, H. Yan and W. C. Wood, Coexistence of high levels of apoptotic signaling and inhibitor of apoptosis proteins in human tumor cells: Implication for cancer specific therapy. Cancer Res. $\mathbf{6 3}$, 6815-6824 (2003).

26. M. J. Boucher, J. Morisset, P. H. Vachon, J. C. Reed, J. Laine and N. Rivard, MEK/ERK signaling pathway regulates the expression of $\mathrm{Bcl}-2, \mathrm{Bcl}-\mathrm{X}_{\mathrm{L}}$, and $\mathrm{Mcl}-1$ and promotes survival of human pancreatic cancer cells. J. Cell. Biochem. 79, 355-369 (2000).

27. M. R. Bhonde, M. L. Hanski, R. Magrini, D. Moorthy, A. Muller, E. A. Sausville, K. Kohno, P. Wiegand, P. T. Daniel and C. Hanski, The broad-range cyclin-dependent kinase inhibitor UCN-01 induces apoptosis in colon carcinoma cells through transcriptional suppression of the Bcl- $\mathrm{x}_{\mathrm{L}}$ protein. Oncogene 24, 148-156 (2005). 